\title{
28 Research Square \\ Study of the factors influencing material properties on energy absorbing devices
}

\section{Dong An}

North China University of Technology

Tianwang Liu

North China University of Technology

Hewei Cui

North China University of Technology

Zheng Chen ( $\nabla$ IMcz54cz@163.com)

North China University of Technology

Hailiang Xu

North China University of Technology

Yimin Song

North China University of Technology

\section{Research Article}

Keywords: Energy absorption device, Material properties, Rock burst, Numerical simulation

Posted Date: February 9th, 2022

DOI: https://doi.org/10.21203/rs.3.rs-1285044/v1

License: (c) (i) This work is licensed under a Creative Commons Attribution 4.0 International License.

Read Full License 


\section{Abstract}

A pre-folded energy absorption device is used to support energy absorption in mining engineering. Due to the change of material properties of the pre-folded energy absorption device during steel processing, the force-displacement curves of the quasi-static compression test and numerical simulation are inconsistent. In this paper, ABAQUS numerical simulation method is used to study the influence of material properties changes in each region on the force-displacement curve of the energy absorption device. It is found that the material properties of each area have an effect on the first drop stage and the second rise stage of the force-displacement curve. $M$ area of the material properties change has an effect on the peak force-displacement curve; from the perspective of the evaluation index, the change of material properties in each area has an improvement effect on the average load, load efficiency, and specific energy absorption. 01-02-M has the highest improvement effect, which is $34.27 \%, 32.81$ \%खand $34.30 \%$ higher than IM, respectively.

\section{Introduction}

The increasing deep mining of coal resources has brought about the frequent occurrence of rock burst accidents. It poses a serious threat to coal mine production and personnel safety. Underground coal mine rock burst refers to the dynamic phenomenon of the sudden and violent destruction of the rock around the shaft or working face due to the instantaneous release of elastic deformation energy, often accompanied by coal and rock body throwing, loud noise,and airwaves. It is very destructive, and is one of the major disasters in coal mines. The effective prevention and control technology of rock burst is the support method ${ }^{[1]}$, which increases the support strength or improves the support method to improve the ability of the support body to resist the rock burst, which is a passive protection method, such as the rigid-

flexible coupling support method ${ }^{[2,3]}$, supporting bolt system and U-shaped steel support method ${ }^{[4,5]}$, the portal type hydraulic support method ${ }^{[6-9]}$, Constant resistance and large deformation bolt support method ${ }^{[10-12]}$ and so on. However, all the above theories on roadway support are based on static analysis, and the research and application of roadway support theory considering the dynamic load of rock burst is still less, so a new type of roadway hydraulic support for rock burst prevention is proposed and developed ${ }^{[13,14]}$.

Energy absorption support is an important method to solve the impact failure of the support body during rock burst ${ }^{[15]}$. Energy absorbing device is a key part of the support in the energy absorption support system. It can release the impact of the surrounding rock by rapid yield and protect the support system from damage ${ }^{[16]}$. Energy absorbing devices play an important role in the field of transportation such as vehicle crash prevention, support role in the process of aircraft cargo hold crash, and crash prevention role in modern rail vehicle collision ${ }^{[17-21]}$. The energy absorbing devices appears as a progressive fold in axial compression, and the plastic deformation of the fold can absorb a large amount of energy. ${ }^{[22]}$ In recent years, many experts and scholars have optimized the design of the energy-absorbing capacity of the energy absorbing devices, such as optimizing the cross-sectional configuration of the structure $[23,24]$ 
and introducing fillers in the structure ${ }^{[25-27]}$. Optimization of the energy absorbing devices using different materials is also considered, such as honeycomb material[ ${ }^{[28]}$, negative Poisson's ratio metamaterial[29], and three-dimensional mechanical metamaterial ${ }^{[30]}$.

In mining engineering, the energy absorbing device often uses a kind of pre-folded energy absorption device, and The position of the energy absorption device is shown in Figure 1. However, scholars have rarely studied the effect of changing the material properties of each part on the energy absorbing device

of the pre-folded box ${ }^{[31,32]}$. Therefore, the folding process and mechanical properties of a pre-folded tube are studied by quasi-static compression test and simulated by ABAQUS, the characteristics and causes of the force-displacement curve of the energy absorbing device are analyzed, the influence of material properties on the force-displacement curves is studied, the influence of each part of the energy absorbing device on the force-displacement curve is evaluated, and the method to achieve the goal of constant resistance of the energy absorbing device is proposed. The maximum load capacity, average load capacity, total energy absorption,and specific energy absorption are important indicators for evaluating energy absorbing devices, which determines the merit of the energy absorption effect ${ }^{[3]}{ }^{[3]}$ The reasons for certain differences in force-displacement curves between test and simulation results are discussed in terms of the influence of material properties on the pre-folded energy absorbing device, and finally, according to the influence of four evaluation indexes on the change of material properties of each part of pre-crease energy absorption device.

\section{Device}

\subsection{Application}

The energy absorbing mentioned above is applied in the coal mine. The coal mine is located in Changcun Mine, Yima, Henan Province, China. The roadway is jointly supported by anchor mesh, anchor rods, anchor cables, hydraulic lifting sheds,and hydraulic support for rock burst prevention.

There was a mining earthquake event in 2016, and the earthquake caused the mechanical pressure gauge on the column in the two hydraulic supports for rock burst prevention to burst and damage, but the surrounding rock supported by the bracket did not have obvious deformation, and the structure of the bracket did not show any signs of damage, which shows that this event had a certain impact on the roadway in the bracket support area, but the bracket effectively resisted the dynamic process of the surrounding rock triggered by this mining earthquake. The Site view of the roadway is shown in Figure 2 .

\subsection{Energy absorbing box}

The energy absorbing box is shown in Figure3.

The design idea of the prefolded square cylinder is derived from origami, and the change of the angle of its inclined folds corresponds to the change of the shape of the cylinder wall plate and the height of the cylinder. Since the deformation of the prefolded square is a fixed pattern and predictable, it can be 
applied as a parameterizable energy-absorbing member by studying the relationship between its geometric relationship, material properties, and the buckling characteristics of the prefolded square structure. ${ }^{[34]}$

\subsection{Production method}

The production method of square tube pre-folded pattern is simpler compared to the complex energy absorbing devices such as notch typ $\mathrm{e}^{[35]}$ and composite type $\mathrm{e}^{[36]}$. The key component of the hydraulic support for rock burst prevention is a structural part with special geometry, and its mechanical properties and energy absorption effect have a crucial influence on the rock burst prevention performance of the hydraulic support. The steel plate used for processing the collision avoidance parts is very thick, which could not be formed by bending and pressing a whole steel plate (there is no one-off forming process that can support the processing of this shape). Therefore, we used the method of welding two half-shells together as a single unit to process the impact protection member. As shown in Figure 4. The steps are as follows:

Firstly, steel plate cutting is carried out: according to the geometric parameters of the pre-folded square tube specimen, the size of the rectangular steel plate required for its half shell is determined. Waterjet cutting or wire cutting is used for cutting, and a certain amount of milling process is reserved for the edge. The second step for bending and pressing of the half-shells: A set of dies and their accompanying presses are used to bend the half-shells of the pre-folded square tube specimens. In order to prevent excessive damage during bending, the steel plate should be preheated before bending and then placed on the die and bent for 10 minutes. Step three for edge trimming: After the half shell of the pre-folded square tube specimen is cooled, it is placed on a milling machine and the top and bottom ends and the edges of the left and right sides are milled away to retain the exact geometry. The fourth step is butt welding: the 2 half-shells are joined and welded with a high-strength welding rod ( $\geq 1000 \mathrm{MPa}$ ) to make a complete prefolded square tube specimen. Final heating treatment. The formed pre-folded square tube specimens are first quenched and then tempered, mainly to eliminate the residual stresses at the bend of the steel plate and near the weld seam.

The square tube pre-folded energy absorption box is made of Q690 ${ }^{[37]}$ high strength steel plate. In the production process, the wall thickness of the pre-folded square tube is $10 \mathrm{~mm}$. A hydraulic servocontrolled testing machine with model number RLJW-2000 is used for loading by means of displacement loading, and the whole test process is photographed.

\section{Impact}

\subsection{Simulation Software}

ABAQUS is a powerful suite of finite element software for engineering simulation, with problem-solving ranging from relatively simple linear analysis to many complex nonlinear problems.ABAQUS includes a rich library of cells that can simulate arbitrary geometries. It also has a library of material models of various types that can simulate the properties of typical engineering materials, including metals, rubber, 
polymers, composites, reinforced concrete, compressible hyperelastic foam, and geological materials such as soil and rock, and can be used to study the effects of unused material properties on structures. As a general-purpose simulation tool, ABAQUS can solve a large number of structural (stress/displacement) problems, including solving problems with large structural deformations ${ }^{[38]}$.

\subsection{Simulation}

In the simulation, density, elasticity,and plasticity are used to describe the strength/strain criterion of the material, and the dimensions and materials of the device are consistent with the experimental results. A downward-displaced rigid plate is set at the top of the device to replace the compressed rigid plate with a displacement rate consistent with the test loading rate. A fixed rigid plate is set at the bottom of the device. The device and the rigid plate are in a frictional contact relationship with a friction coefficient of 0.4. The energy absorbing device uses a steel density of $7650 \mathrm{~kg} / \mathrm{m} 3$, an elastic modulus of $207 \mathrm{GPa}$, a Poisson's ratio of 0.3 , yield strength of $690 \mathrm{MPa}$. The model is divided into 7536 grid cells. The numerical model is shown in Figure5.

The accuracy of the ABAQUS calculation is affected by the mesh ${ }^{[39]}$, as shown in Figure 6. The energyabsorbing device studied in this paper is a large deformation structure, and it is necessary to carry out mesh optimization analysis to compare the influence of mesh accuracy, $4 \mathrm{~mm}$ is suitable, as shown in Figure 7.

\section{Quasi-static Compression Test And Numerical Simulation 4.1 Test Overview}

A quasi-static compression test was conducted on the energy absorbing device, and the loading system adopts a self-made hydraulic impact testing machine to carry out displacement control loading at about $8 \mathrm{~m} / \mathrm{s}$ compression rate. The whole process of the test was photographed by high definition, and the deformation process was observed. At the same time, the displacement deformation and impact pressure were collected. The energy absorbing device is made of $\mathrm{Q} 690^{[40]}$ high-strength steel plates rolled and welded.

\subsection{Test curve}

The force displacement curve of the compression process of the energy absorbing device is shown in Figure 8, which is of "W" type with up and down fluctuation. The yield load of the device is $4966.8 \mathrm{kN}$, the minimum load capacity during deformation is $2539.4 \mathrm{kN}$, and the average yield load capacity is 3576.2 $\mathrm{kN}$.

The initial elastic deformation of the device occurs, and the load-bearing capacity rises rapidly with a little deformation. The wrinkle area in the middle of the component first deforms, and the convex and concave wrinkles deform outward and inward respectively under extrusion. The upper half of the component 
collapses, and the folding area generates stack deformation. After the upper port is folded, the lower part of the component begins to collapse until the whole component is completely collapsed. It is proved that the component has a stable deformation energy absorption process.

\subsection{Force-Displacement curves}

The comparison of force-displacement curves between test and numerical simulation is shown in Figure 9. The peak valley bottom of the curve is taken as the key point for analysis. The peak values of the first rising curve are $3115290 \mathrm{~N}$ and $3020513 \mathrm{~N}$, respectively, with a difference of $3.0 \%$. The valleys of the first falling curve were $1604219 \mathrm{~N}$ and $1529771 \mathrm{~N}$, respectively, with a difference of $4.6 \%$. The peaks of the second curve rising section test and simulation are $2364527 \mathrm{~N}, 2797265 \mathrm{~N}$, respectively, with a difference of $15.5 \%$. In general, the fluctuation trend of the two groups is basically the same, and the maximum error of the extreme value position is within $20 \%$ of the test value.

Although the trends of force-displacement curves obtained from field tests and numerical simulations are approximately the same, the material properties are changed due to bending and overheating during steel reprocessing in field tests, while the material properties in numerical simulations are unified, which leads to the curve is not completely consistent. Therefore, in order to explore in-depth the reasons for the differences in the force-displacement curves obtained from the field tests and numerical simulations, the effects of changing the material properties of each part of the square pre-folded energy-absorbing structure on the force-displacement curves were obtained by changing the material properties of different regions.

\section{Influence Of The Energy Absorbing Member Area 5.1 Regional division}

In the specimen production process, the strength of the specimen is increased during the steel processing ${ }^{[41]}$, while the strength of the specimen is decreased by heat treatment ${ }^{[42]}$. The calculation is simplified, and the steel strengthening section is taken to analyze the material. According to the characteristics of the square pre-folded energy absorbing device and the influence of each region on the force-displacement curve during the deformation process, the energy absorbing device is divided into several different regions, and the influence of the change of material properties on the force-displacement curve of the energy-absorbing device is investigated by changing the material properties of one region at a time. A total of four regions are divided into four regions, which are explained below: the upper and lower open regions, the four corner parts of the concave surface are 01 regions, and the other regions are $\mathrm{O} 2$ regions; the middle part as a whole is $\mathrm{M}$ region; the surrounding prismatic part is divided into $\mathrm{RL}$ regions; the initial model is IM; the schematic diagram is shown in Figure 10.

\subsection{Work conditions}

Each condition is numbered by the area included in this condition and the width dimensions of these areas, and the calculation conditions used in this paper are shown in Table 1. 
Table 1

Calculated working conditions

\begin{tabular}{|llllll|}
\hline Work conditions & Number & O1/mm & O2/mm & M/mm & RL/mm \\
\hline 1 & IM & 0 & 0 & 0 & 0 \\
2 & $01-10$ & 10 & 0 & 0 & 0 \\
4 & $01-15$ & 15 & 0 & 0 & 0 \\
5 & $01-02-10$ & 10 & 10 & 0 & 0 \\
6 & $01-02-15$ & 15 & 15 & 0 & 0 \\
7 & $\mathrm{M}-10$ & 0 & 0 & 10 & 0 \\
8 & $01-02-\mathrm{M}-10$ & 10 & 10 & 10 & 0 \\
\hline
\end{tabular}

\subsection{Area}

The effect of changing the material properties at different width corners (01 part) on the forcedisplacement curve of the square pre-folded energy-absorbing structure is considered ${ }^{[43]}$. Combined with the loading and constraint method of the initial specimen experiment, the numerical simulation analysis of working conditions 1-3 is carried out.

According to the numerical simulation results, the force-displacement curve of the energy absorption device under displacement loading is extracted to facilitate the comparative analysis of the energy absorption characteristics of the energy absorption device under different conditions. As shown in Figure 11.

It can be seen from Figure 11 (a) that when 01part changes the material, compared with the initial model, the initial stress does not change. The first decline stage of 01-10 and 01-15 is significantly earlier than the initial model. The displacement of 01-10and 01-15 to the peak valley bottom is significantly advanced by about $10 \mathrm{~mm}$ and $5 \mathrm{~mm}$. Before and after the displacement of $80 \mathrm{~mm}$ can be seen, before the displacement of $80 \mathrm{~mm}$, the curve is higher than the initial model curve, the maximum difference is about $1500 \mathrm{kN}$; after the displacement of $80 \mathrm{~mm}$, the curve is lower than the initial model curve, the maximum difference is about $1100 \mathrm{kN}$. With the increase of the width of the 01 part, the first decline section and the second rise section of the curve tend to be flat, indicating that the 01 part affects the first decline section and the second rise section of the structural force-displacement curve. The force-displacement curve is in line with the law of field experiments. The first decline stage and the second decline stage are respectively loaded by the upper and lower openings (01 part).

The influence of different material properties at the openings (01 and 02) on the force-displacement curve of the square pre-folded energy absorption device is considered and compared with the 01 part to 
explore the influence of the 02 part. Combined with the loading and constraint method of the initial sample experiment, the numerical simulation analysis of working conditions 2-5.

It can be seen from Figure 11 (b) that the initial stress did not change after the material properties of part 02 changed, and the overall trend was basically consistent with that of only part 01 . When the width of the 01 part is $10 \mathrm{~mm}$, in the displacement between $20 \mathrm{~mm}-40 \mathrm{~mm}$, changing the 02 part of the material, the curve decreased significantly lower and faster, the maximum difference is about $300 \mathrm{kN}$, in the displacement between $50 \mathrm{~mm}-80 \mathrm{~mm}$, the curve increased significantly higher, the maximum difference is about $800 \mathrm{kN}$, and the peak of the rise and fall stage is in advance. However, when the width of the 01 part is $15 \mathrm{~mm}$, the curve basically does not change after changing the material of 02 . This shows that the 02 part affects the first descending section and the second ascending section of the structural forcedisplacement curve. The force-displacement curve is in line with the law of field experiments. The first decline stage and the second decline stage are respectively loaded by the upper and lower openings (02 part).

The influence of different material properties of the middle part ( $M$ part) on the force-displacement curve of the square pre-folded energy absorption device is considered and compared with the initial model. Combined with the loading and constraint methods of the initial sample experiment, the numerical simulation analysis of working condition 1.6 was carried out.

It can be seen from Figure 11 (c) above that when compared with the curve of the initial model (IM), the initial stress is significantly improved after the material properties of part $\mathrm{M}$ are changed. In the first decline stage, the curve is gentle and the valley bottom is obviously advanced and improved. The curve is lower than the initial model curve before the displacement of $40 \mathrm{~mm}$, and the maximum difference is about $500 \mathrm{kN}$. After the displacement of $40 \mathrm{~mm}$, the curve is higher than the initial model curve, and the maximum difference is about $700 \mathrm{kN}$. In the second rising stage, the peak value of the curve obviously delayed and decreased, with a maximum decrease of about $500 \mathrm{kN}$, and the curve was flat. It shows that the first rising stage bears the load from the middle part, which conforms to the experimental law.

The influence of different material properties of the edge part ( $R L$ part) on the force-displacement curve of the square pre-folded energy absorption device was considered and compared with the 01-02-M working condition. ${ }^{[44]}$ Numerical simulations are carried out for working condition 7.8 in conjunction with the loading and restraint methods of the initial specimen experiments.

It can be seen from Figure 11 (d) that the initial stress does not change when the material properties of the RL part change. The first decline and the second rise of the curve were more stable, and the peak valley bottom of the first decline stage decreased significantly and was delayed by about $10 \mathrm{~mm}$. In the displacement between $20 \mathrm{~mm}-40 \mathrm{~mm}$, the curve is obviously improved, the maximum increase is about $600 \mathrm{kN}$, in the displacement between $50 \mathrm{~mm}-60 \mathrm{~mm}$, the curve is obviously reduced, the maximum decrease is about $1000 \mathrm{kN}$.

\section{Evaluation Indicators}




\subsection{Indicator Description}

The reaction force of the energy-absorbing device under the action of impact load will also fluctuate with the change of let displacement, based on the performance requirements of different stages, for the reaction there are four indicators of peak load, average load, load efficiency, and specific energy absorption ${ }^{[45]}$, the following indicators are described:

(1) Peak load

$$
F \max =\max [F(s)]
$$

1

In equation (1), $F(s)$ is the time history function of the reaction force in the process of giving way. The peak load $F_{\max }$ is the threshold value when the energy absorbing member starts to give way to energy absorption under the action of impact load, and its value represents the difficulty of the start of the give way work and the stability of the mechanism during normal work.

(2) Average load

$$
F_{\text {mean }}=\frac{\int F(\mathrm{~s}) \mathrm{d} s}{S}
$$

2

In equation (2), $\mathrm{S}$ is the total displacement of the absorbing position of the energy absorbing member. $F_{\text {mean }}$ is the energy absorption per unit compression displacement, which reflects the overall energy absorption capacity of the energy absorption component.

(3) Load efficiency

$$
F_{\mathrm{E}}=\frac{F_{\text {mean }}}{F_{\text {max }}}
$$

3

The loading efficiency is the ratio of the average load to the peak load, $\mathrm{F}_{\mathrm{E}} \in(0,1)$. The smaller the value, the stronger the volatility of the reaction force during the absorption position, and the closer it is to 1 , the more stable it is.

(4) Specific energy absorption

$$
S E A=\frac{E}{m}
$$


In equation (4), $m$ is the total mass of the energy absorption device, and $E$ is the total energy absorption of the energy absorption component, which is calculated by the equation (5):

$$
E=\int F(s) \mathrm{d} s
$$

5

\subsection{Indicator Description Results and Analysis}

According to the formula of the four evaluation indicators stated above, each evaluation indicator for each working condition is calculated, and the calculation results are shown in Table 2.

Table 2

Evaluation Indicators

\begin{tabular}{|llllll|}
\hline $\begin{array}{l}\text { Work } \\
\text { conditions }\end{array}$ & Number & $\begin{array}{l}\text { Peak load } \\
/ \mathbf{k N}\end{array}$ & $\begin{array}{l}\text { Average load } \\
/ \mathbf{k N}\end{array}$ & $\begin{array}{l}\text { Load } \\
\text { efficiency }\end{array}$ & $\begin{array}{l}\text { SEA } \\
/ \mathbf{k J}^{*} \mathbf{k g}^{-1}\end{array}$ \\
\hline 1 & $\mathrm{IM}$ & 3049.64 & 1940.46 & 0.64 & 31.84 \\
\hline 2 & $01-10$ & 3056.12 & 2556.93 & 0.84 & 41.96 \\
\hline 3 & $01-15$ & 3046.42 & 2514.92 & 0.83 & 41.27 \\
\hline 5 & $01-02-10$ & 3062.13 & 2576.31 & 0.84 & 42.28 \\
\hline 6 & $01-02-15$ & 3048.15 & 2501.49 & 0.82 & 41.05 \\
\hline 7 & $\mathrm{M}-10$ & 3214.36 & 2504.54 & 0.78 & 41.10 \\
\hline 8 & $01-02-\mathrm{M}-10$ & 3059.49 & 2605.51 & 0.85 & 42.76 \\
\hline
\end{tabular}

(1)From the influence of the 01 part, compared with the evaluation indexes of working conditions 1-3, when the material properties of the 01 part change, the peak load basically does not change, and the 01 part does not affect the fluctuation of the peak load. Compared with the initial model, the absorbed energy per unit compression displacement of 01 material after the change of material properties is significantly increased by $31.76 \%$ and $29.60 \%$, respectively. The loading efficiency shows that the fluctuation of reaction force in the process of energy absorption and transfer is $31.25 \%$ and $29.69 \%$ higher than that of the initial model, respectively. The force-displacement curve of the 01 part is more stable after the change of material properties. The energy absorbed by the unit weight of the structure after the change of the material properties of part 01 is significantly improved, which is $31.78 \%$ and $29.62 \%$ higher than that of the initial model, respectively.

(2)From the point of view of the influence of the 02 part, compared with the evaluation index of the working condition 2-5, the peak load is basically unchanged when the material properties of the 02 part change, and the 02 part does not affect the fluctuation of the peak load. The energy absorption on unit 
compression displacement after the change of material properties in part 02 is basically unchanged compared with that in part 01 , and the change range of material properties in part 02 has little effect on the average load. The change of material properties in part 02 has little effect on the fluctuation of the force-displacement curve, and the change range of material properties has little effect on the fluctuation of the force-displacement curve. The energy absorbed by the unit weight of the structure does not change after the change of $\mathrm{O} 2$ material properties.

(3)From the influence of $M$ part, compared with the evaluation index of working condition 1.6, the peak load of the $\mathrm{M}$ part is obviously improved when the material properties of the $\mathrm{M}$ part are changed, which is $5.4 \%$ higher than the IM, indicating that $\mathrm{M}$ part has a certain influence on the fluctuation of peak load. Compared with the initial model, the energy absorption on the unit compression displacement after the change of material properties in part $M$ increases by $29.07 \%$, indicating that the change of material properties in part $M$ has a certain influence on the average load. The change of material properties of the $\mathrm{M}$ part has a certain influence on the fluctuation of the force-displacement curve, which reduces the fluctuation of the force-displacement curve and improves the load efficiency by $21.88 \%$. The energy absorbed by the unit weight of the structure is increased by $29.08 \%$ after the material properties of part $M$ are changed, indicating that the material properties of part $\mathrm{M}$ can improve the energy absorbed by the unit weight of the structure.

(4)From the influence of the RL part, compared with the working condition 7.8 evaluation index, the peak load of the RL part is basically unchanged when the material properties of the RL part change, indicating that the RL part has no effect on the fluctuation of the peak load. The energy absorption on unit compression displacement of RL part after the change of material properties is lower than that of 01-02$\mathrm{M}$ part, which is $3.60 \%$ lower, indicating that the change of material properties of RL part has a certain influence on the average load. The change of material properties in RL has little effect on the fluctuation of the force-displacement curve; the energy absorbed by the unit weight of the structure decreases by $3.6 \%$ after the change of the material properties of the $\mathrm{RL}$ part, indicating that the material properties of $\mathrm{M}$ part can reduce the energy absorbed by the unit weight of the structure.

\section{Conclusion}

(1) In the field experiment, due to the bending and overheating in the steel reprocessing process, the local material properties have changed, and the material properties in the numerical simulation are unified, which leads to the curve not being completely consistent. By changing the material characteristics of different regions, it is found that the 01 part makes the first drop and the second rise stage of the forcedisplacement curve more gentle, and the peak value of the second rise stage is significantly reduced. The 02 part makes the force-displacement curve decrease obviously in the first drop stage and increase obviously in the second rise stage. The $\mathrm{M}$ part makes the peak value of the force-displacement curve increase obviously, and the first decline and the second rise stage are more gentle. The RL part obviously makes the first decline and the second rise of the force-displacement curve smoother. 
(2) Through the evaluation index of the energy absorption device, it is found that part $\mathrm{M}$ can significantly improve the peak load of the force-displacement curve of the energy absorption device, increasing by $5.4 \%$. Each area can significantly improve the energy absorption per unit compression displacement of the energy absorption device, with 01-02-M increasing the most, by $34.27 \%$ compared with IM; Each area can significantly reduce the fluctuation of the force-displacement curve, and the load efficiency increases most by $01-02-\mathrm{M}$, which is $32.81 \%$ higher than that of IM; Each area can significantly increase the energy absorbed by the unit weight of the structure. The specific energy absorption increases most by 01-02-M, which is $34.30 \%$ higher than that of IM.

\section{Declarations}

Data availability statement

All data, models, or code that support the findings of this study are available from the corresponding author upon reasonable request.

\section{References}

1. Jiang YD, Pan YS, Jiang FX, et al. State of the art review on mechanism and prevention of coal bumps in China[J]. Journal of China Coal Society, 2014, v.39; no.233 (02) : 205-213.

2. Lv XF, Pan YS and Li ZH. Rigid-flexible Energy Absorbing Structure with Porous Metal Material and Its Application to Roadway Support of Rockburst[J].Journal of Disaster Prevention and Mitigation Engineering, 2011,31 (02): 185-190.

3. Lv XF and Pan YS. Stress wave propagation and decay law and test analysis of surrounding rock by rigid-flexible coupling support[J]. Engineering mechanics, 2013,30 (01): 345-349.

4. Cheng YH, Jiang FX, Hu ZF, et al. Prevention and control of coal burst on gob-side entry in deep coal seam with fully mechanized sublevel caving mining[J].Chinese Journal of Rock Mechanics and Engineering, 2016,35 (S1): 3000-3007.

5. Zhang N, Kan JG and Yang S. Control technology and failure types of anchor bolt support and Usteel frame support[J]. Coal science and technology, 2015, v. 43; no.487 (06) : 41-47.

6. Pan YS, Xiao YH and Li GZ.Roadway hydraulic support for rockburst prevention in coal mine and its application[J].Journal of China Coal Society, 2020,45 (01): 90-99.

7. Xu WJ and Gu HJ. Heighten of Rock Burst Pcrformance of Hydraulic Support in Mine[J]. Coal technology, 2009,28 (09): 23-24.

8. Yu ZH and Guan WT.Take comprehensive measures to use anti-shock roadway support to ensure safe production in severe rock burst areas [J].Opencast Mining Technology, 2013 (05): 81-84.

9. Zhang Y,Wang J,Wei HY,et al.Study on temporary portal type support technology in impact area of roof cutting by gob-side entry retaining[J].Coal science and technology, 2018 (S1): 5. 
10. Kohlböck B.,Mayer A.,Schnabl R.,et al.Geotechnik, Vortrieb und Stuetzung der zweiten Roehre des Tauerntunnels und Vergleich mit der ersten Roehre / Geotechnics, tunnelling and support of the second tube of the Tauern Tunnel and comparison with the first tube[J]. Geomechanics \& Tunnelling, 2010, 3:343-353.

11. Wei L,Liu Q and Huang P. Research Progress on Large Deformation Mechanism and Control Countermeasures of Soft Rock Tunnel in High Ground Stress[J]. Highway, 2017,62 (07):297-306.

12. He MC,Li C,Gong WL,et al.Support principles of NPR bolts/cables and control techniques of large deformation[J]. Chinese Journal of Rock Mechanics and Engineering, 2016, 35 (08): 1513-1529.

13. Pan YS,Xiao YH,Li ZH,et al.Study of tunnel support theory of rockburst in coal mine and its application[J].Journal of China Coal Society, 2014, v.39; no.233 (02) : 222-228.

14. Song YM, Ren $\mathrm{H}, \mathrm{Xu} \mathrm{HL}$, et al. Study on synergistic system of energy-absorbing yielding anti-impact supporting structure and surrounding rock. Sci Rep 12<bi>,</bi> 594 (2022).

15. Pan YS,Xiao MA,Xiao YH, et al. Numerical Analysis and Experimental Study of a Coal Mine AntiImpact and Energy-Absorption Supporting Component[J]. Journal of Experimental Mechanics,2014.

16. Wang KX and Pan YS.An unified theory of energy absorption and anti-impact for surrounding rock and support in rock burst mine. Rock Soil Mech 2015; 36(9):2585-2590.

17. Bloch B S.Improved crashworthy designs for truck underride guards[C]// International Technical Conference on the Enhanced Safety of Vehicles.1998.

18. José Ricardo Lenzi Mariolani.DEVELOPMENT OF NEW UNDERRIDE GUARDS FOR ENHANCEMENT OF COMPATIBILITY BETWEEN TRUCKS AND CARS.2001.

19. Abromowitz A,Smith T G and Vu T.Vertical Drop Test of a Narrow-Body Transport Fuselage Section With a Conformable Auxiliary Fuel Tank Onboard:Final Report.2000.

20. Abramowitz A,Smith T G,Vu T, et al. Vertical Drop Test of a Narrow-Body Transport Fuselage Section with Overhead Stowage Bins[C]//World Aviation Congress \& Exposition.2002.

21. Shuai $W$ and Gao G. Performance of extruded magnesium alloy AZ31B circular tubes under uniaxial compression[J]. Thin-Walled Structures, 2018, 131:464-474.

22. Dipaolo B P and Tom J G.A study on an axial crush configuration response of thin-wall, steel box components: The quasi-static experiments[J]. International Journal of Solids and Structures, 2006, 43(25-26):7752-7775.

23. Tarlochan F,Samer $F$,Hamouda A, et al. Design of thin wall structures for energy absorption applications: Enhancement of crashworthiness due to axial and oblique impact forces[J]. ThinWalled Structures, 2013, 71(oct.):7-17.

24. AA Nia and Hamedani $\mathrm{J} \mathrm{H}$. Comparative analysis of energy absorption and deformations of thin walled tubes with various section geometries[J]. Thin-Walled Structures, 2010, 48(12):946-954.

25. Zarei $\mathrm{H}$ and Krger M. Optimum honeycomb filled crash absorber design - ScienceDirect[J]. Materials \& Design, 2008, 29(1):193-204. 
26. Yalcin M M and Genel K. On the axial deformation characteristic of PVC foam-filled circular aluminium tube: Effect of radially-graded foam filling[J]. Thin-Walled Structures, 2019, 147.

27. Hanssen A G, Hopperstad O S and Langseth M. Design of aluminium foam-filled crash boxes of square and circular cross-sections[J]. International Journal of Crashworthiness, 2001, 6(2):177-188.

28. Al-Ketan O, Rowshan R and AI-Rub R A. Topology-Mechanical Property Relationship of 3D Printed Strut, Skeletal, and Sheet Based Periodic Metallic Cellular Materials[J]. Additive Manufacturing, 2018, 19:167-183.

29. Surjadi J U, Gao L,Du H, et al. Mechanical Metamaterials and Their Engineering Applications[J]. Advanced Engineering Materials, 2019, 21(3).

30. Yuan S,Shen F,Bai J, et al. 3D soft auxetic lattice structures fabricated by selective laser sintering: TPU powder evaluation and process optimization[J]. Materials \& Design, 2017, 120(APR.):317-327.

31. C T N T A, B S H A, B X H A, et al. Theoretical prediction and crashworthiness optimization of multicell triangular tubes[J]. Thin-Walled Structures, 2014, 82(82):183-195.

32. Chen S, Yu H and Fang J. A novel multi-cell tubal structure with circular corners for crashworthiness[J]. Thin-Walled Structures, 2018, 122:329-343.

33. An D, Song JQ, Xu HL, et al. Study on improvement of prefolded energy absorption device to constant resistance and its mechanical properties[J]. Science Progress, 2021, Vol. 104(3) 1-17.

34. Liu YQ, Li X, Cai JG, et al. Study on buckling resistance of Miura origami-based tube[J]. Journal of Southeast University(Natural Science Edition), 2021,51 (05): 733-739.

35. Zhang $X$ and Zhang $H$. Energy absorption of multi-cell stub columns under axial compression[J]. Thin-Walled Structures, 2013, 68:156-163.

36. Pirmohammad S and Marzdashti S E. Crushing behavior of new designed multi-cell members subjected to axial and oblique quasi-static loads[J]. Thin-Walled Structures, 2016, 108(108):291304.

37. GB/T 2975-2018, Steel and steel products-Location and preparation of samples and test pieces for mechanical testing[S].

38. Shi YP and Zhou YR.ABAQUS finite element analysis examples [M].Mechanical Industry Press, 2006.

39. Yao YY, Li Y, Huang G, et al. Research on high speed cold roll-beating based on ABAQUS mesh quality[J]. Journal of Xi ' an University of Technology, 2018, 34 (1): 6.

40. JGJ/T 483-2020,Design standard of high-strength steel structure[S].

41. Ban HY, Shi G, Shi Y, et al.Research advances on mechanical properties of high strength structural steels[J].Building structure, 2013 (2): 8.

42. Wang WY, Zhang YH and Li GQ. Study on nominal values of mechanical properties of high strength structural steel at elevated temperature and after fire exposure[J/OL]. Journal of Building Structures: 1-15 [2022-01-11].

43. Xu HL, Song JM, An D, et al. Local Thickening and Friction Reducing to Constant Resistance in a Prefolded Energy Absorption Device[J]. Shock and Vibration, 2020, 2020(11):1-11. 
44. Zheng YQ, Zhu XC, Hu Q, et al. Mechanical Properties of Thin-walled Square Tube with Strengthened Ridgelines Subjected to Axial Crushing [ J ]. Journal of Tongji University(Natural Science), 2016,44 (06): 949-954.

45. Zhang Y. Structural Optimization Design of Automobile Crash Box Under Low-speed Collision[D]. Dalian University of Technology, 2019.

\section{Figures}

Figure 1

Location of the energy absorption device

\section{Hydraulic shed lift bracket}

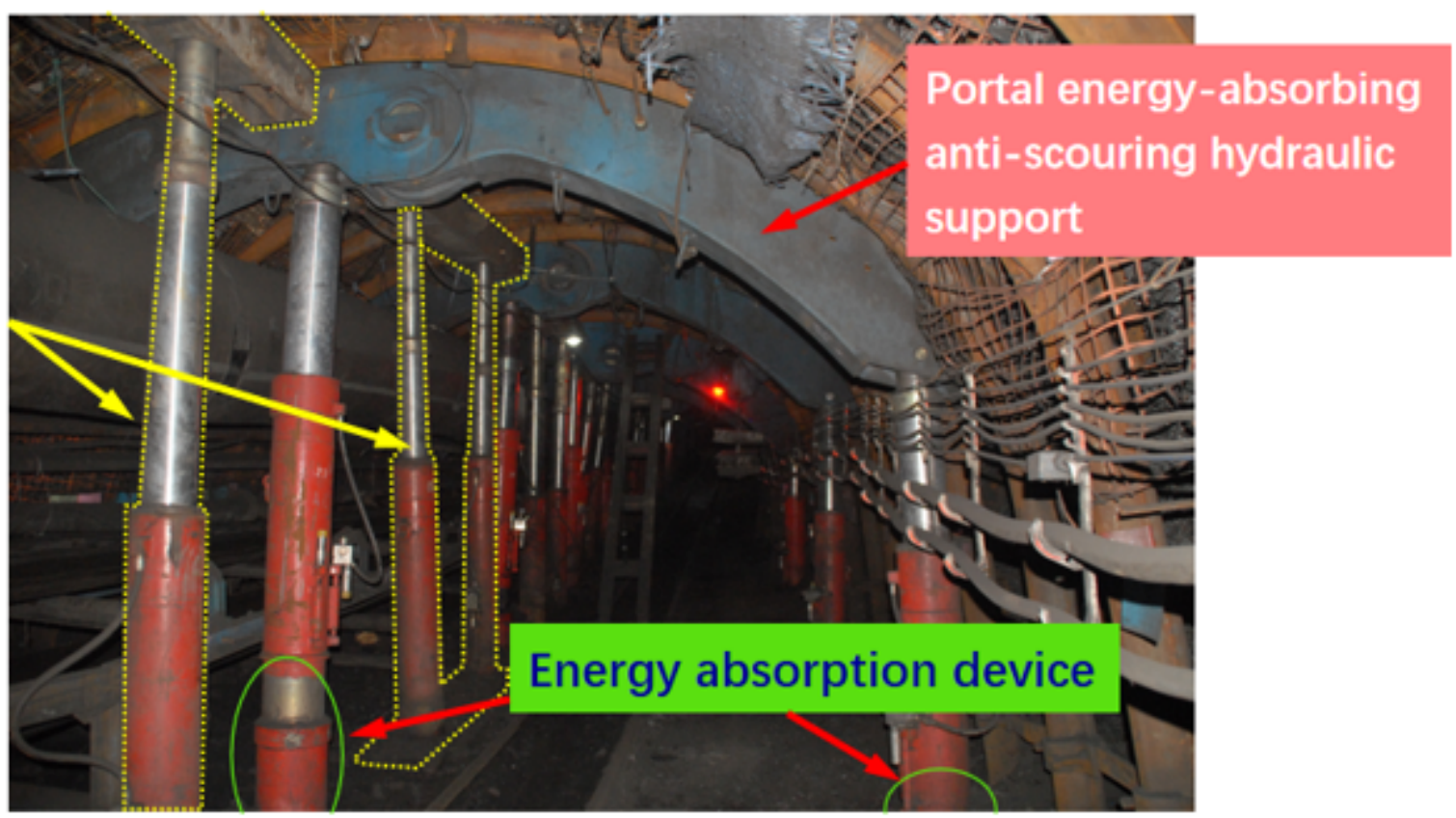

\section{Figure 2}

Site view of the roadway supported by the support frame 

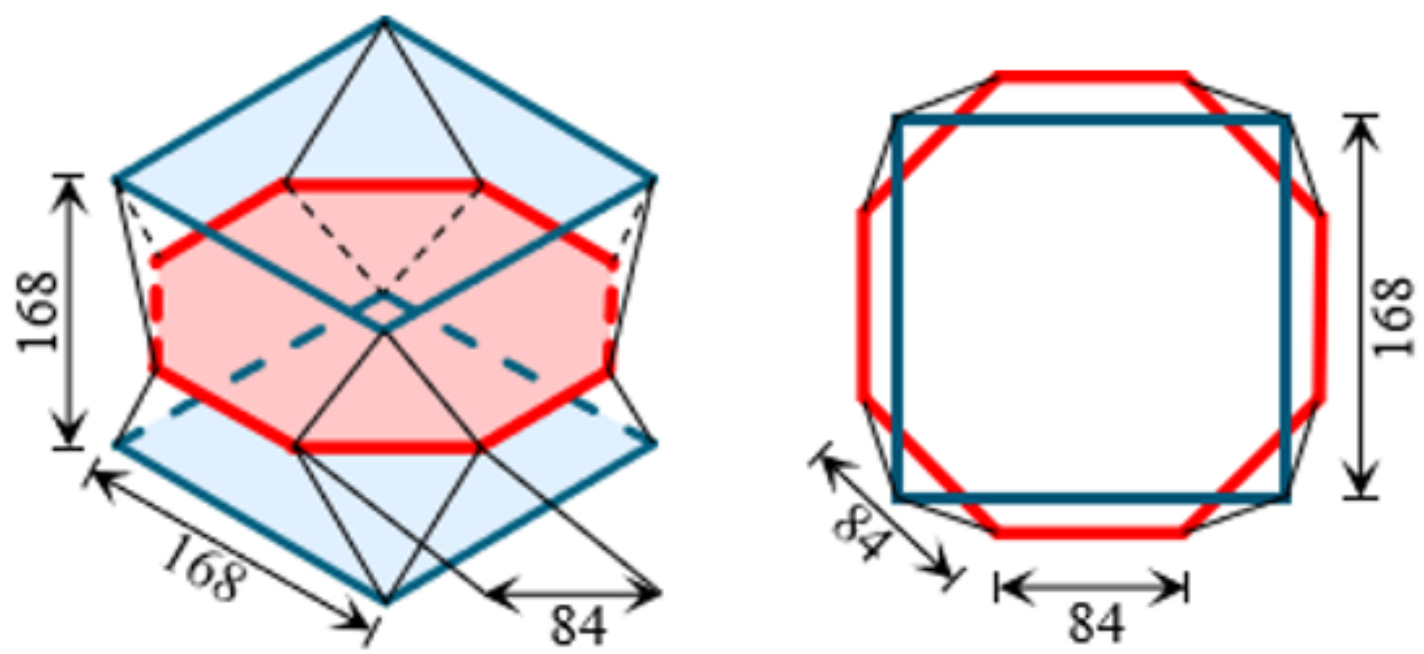

Figure 3

Dimensions of the square tube pre-folded energy absorption device
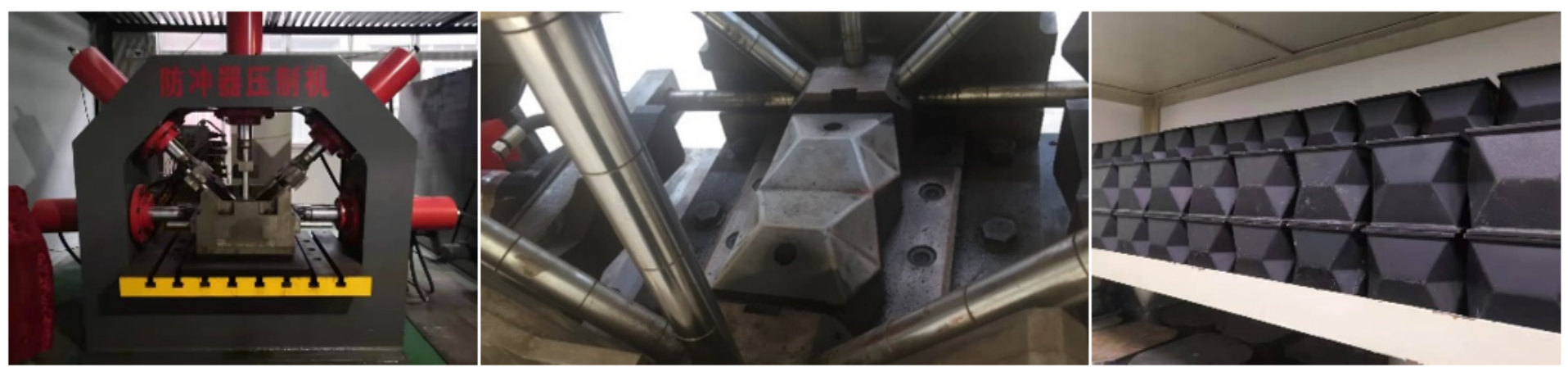

Figure 4

Production flow of energy absorption device for square tube pre-folded device 


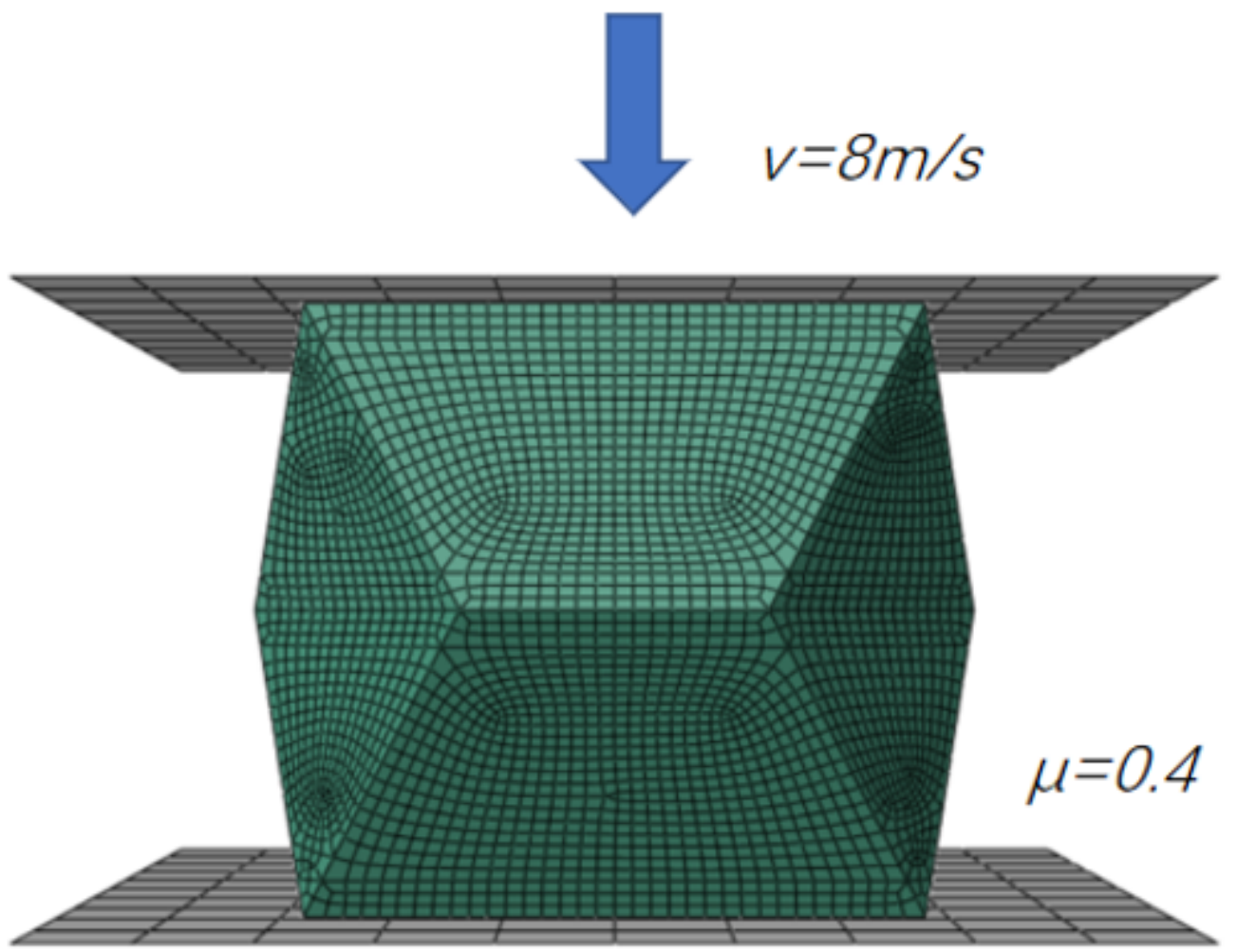

Figure 5

numerical simulation model 


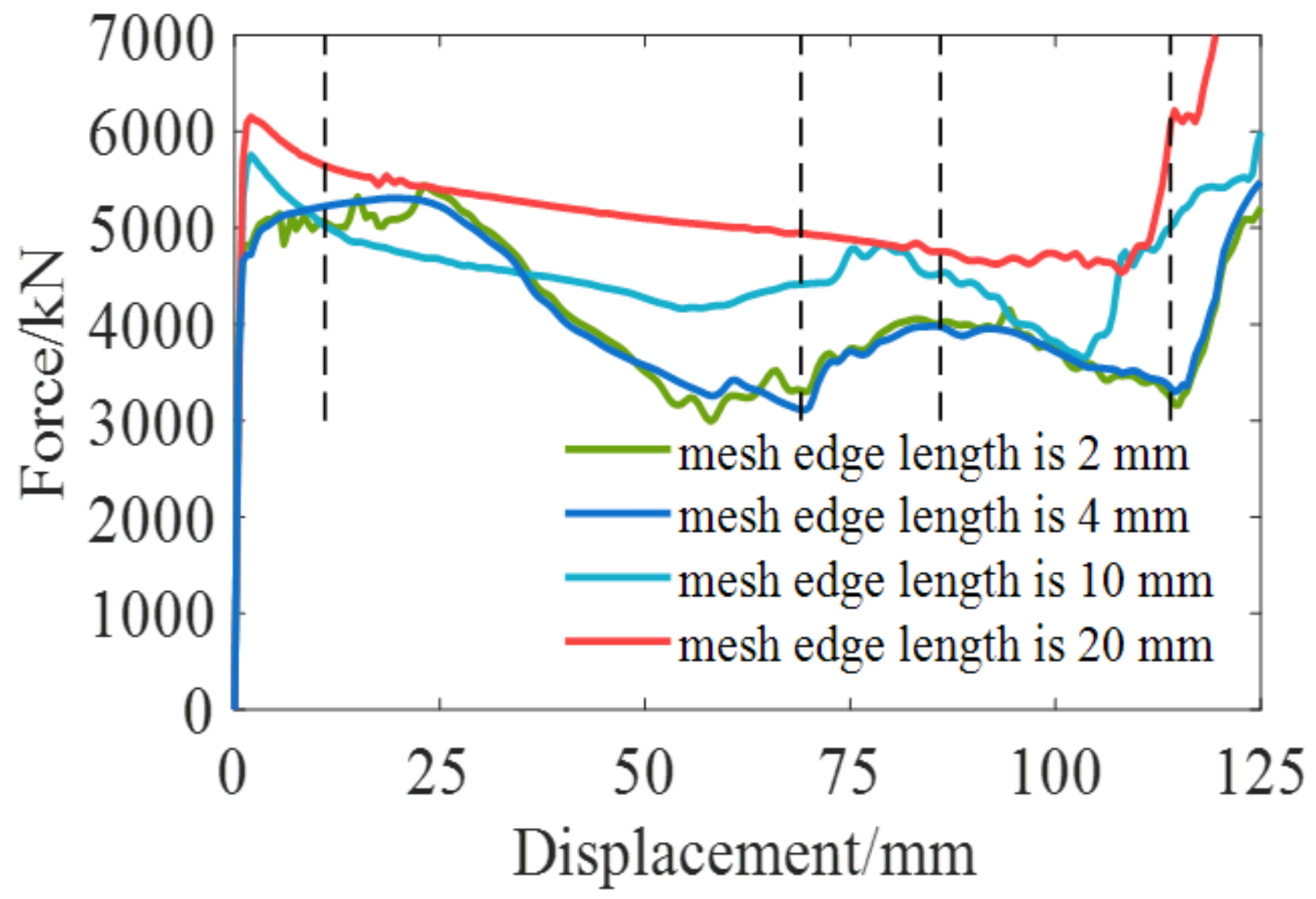

Figure 6

Calculation results for different mesh sizes of prefolded tubes

Figure 7

Results of different mesh size division

Figure 8

Force-displacement curve of test

Figure 9

Error at the extreme position of the force-displacement curves 


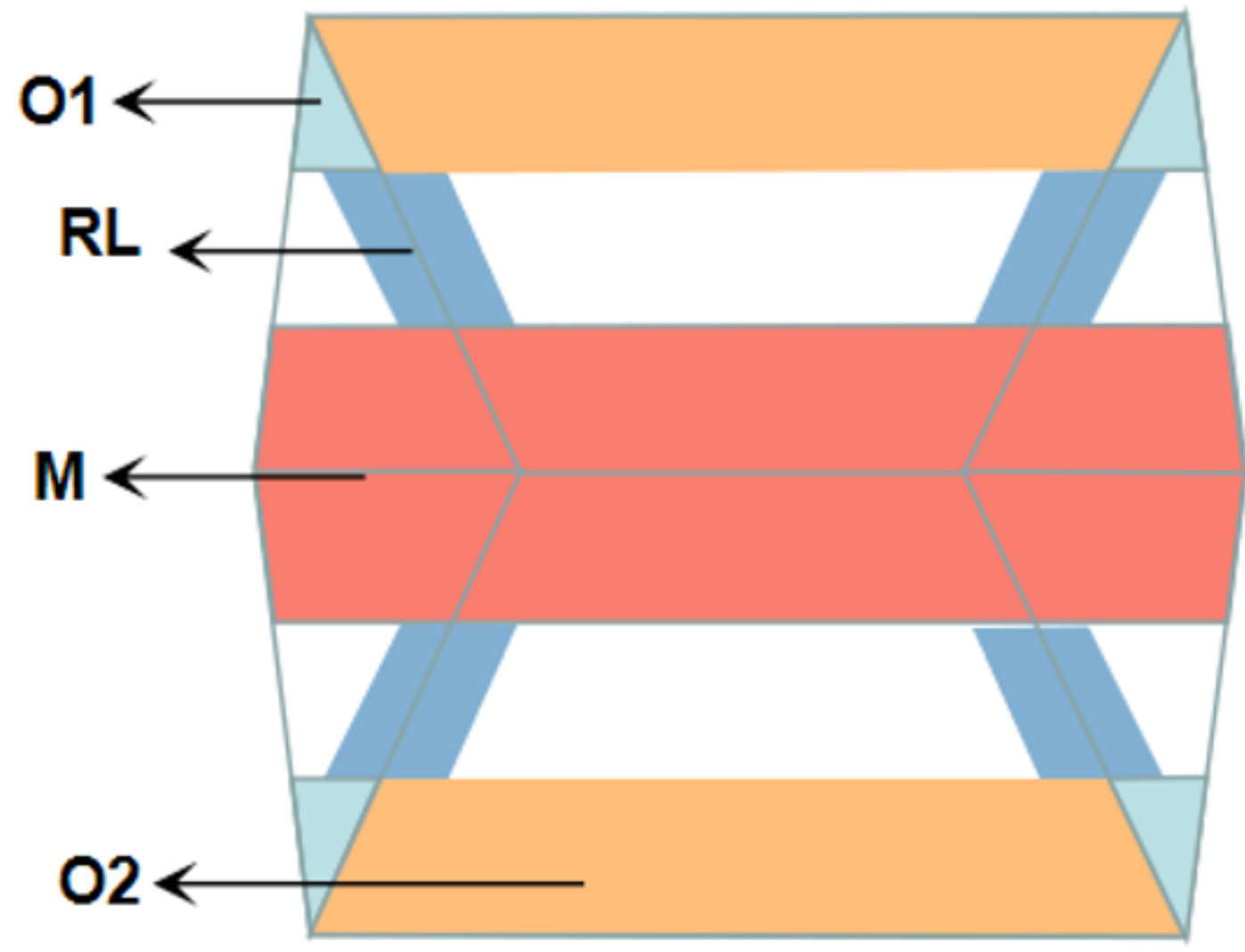

Figure 10

Model partition schematic

Figure 11

Force-displacement curves of each area 